\title{
El relativismo histórico de los géneros literarios
}

\author{
Jorge ALCÁZAR \\ Universidad Nacional Autónoma de México
}

Si nos guiáramos por las etiquetas actuales, uno pensaría que la manera en que concebimos los géneros literarios se ha reducido. En comparación con las fatigosas clasificaciones del pasado, pareciera que el horizonte conceptual, del cual les damos nombre, se hubiese encogido. Sólo basta con asomarse a algún periódico o revista de habla inglesa, o con la lista más reciente de bestsellers, para toparnos con la disyuntiva nominal fiction/nonfiction. Si pudiéramos poner pie, por medio de alguna máquina del tiempo salida de un relato de ciencia ficción, en una librería del Reino Unido de la década de los sesentas, veríamos su contraparte referencial: unos estantes con libros de pasta suave color anaranjado, sumamente ordenados; enfrente otra hilera de anaqueles con volúmenes de cubiertas de un tono indefinido, entre azul, verde y turquesa. Éstos son los colores emblemáticos con los que el sello editorial Penguin solía distinguir de manera ostensible entre narrativa y nonfiction.

Éste es un caso extremo de reduccionismo clasificatorio. Al otro lado estarían las divisiones ultraelaboradas propias del Renacimiento, de las que tenemos un ejemplo cómico en Hamlet, cuando Polonio, con su proclividad lenguaraz, nos informa: "The best actors in the world, either for tragedy, comedy, history, pastoral, pastoral-comical, historical-pastoral, tragicalhistorical, tragical-comical-historical-pastoral, scene undividible, or poem unlimited".'

Nuestras categorias genéricas no serían necesariamente ni más abundantes ni más precisas. Contamos con la triada tradicional de narrativa, poesía y teatro, remedo grosero de la división aristotélica en épica, lírica y drama. Empero, preguntémonos en qué momento tomó carta de naturalidad esta ordenación tripartita. Según indica Michal Glowinski, fue Goethe quien canonizó esta división como si se tratara de formas naturales de la creación literaria que poco

${ }^{1}$ William Shakespeare, Hamlet, II, ii, pp. 395-399. 
a poco adquirieron una suerte dè realidad transhistórica. ${ }^{2}$ Sin embargo, podríamos apelar a otro criterio de clasificación que no echó raíces en la tradición occidental, pero que forma parte - como indica Curtius- de la historia de la teoría literaria en la antigüedad. Me refiero a la división propuesta por Diomedes, que - a diferencia de la de Aristóteles- se basa en criterios de tipo externo. Como es bien sabido, el estagirita sustenta sus categorías genéricas de acuerdo con las propiedades internas observables en una obra. El concepto clave de su modelo descriptivo es el de imitación y sus subsecuentes subdivisiones de acuerdo con los medios utilizados, los objetos representados y el modo de recrearlos. Así, la elegía difiere de la poesía ditirámbica en los medios que emplean; la comedia de la tragedia en los protagonistas objeto de la acción, y la épica de la tragedia en el modo de imitar. Diomedes, por el contrario, elabora sus categorías dependiendo de quién habla en la obra. Establece tres tipos:

1) Genus actiuum uel imitatiuum (cuando el poema no contiene intervenciones del poeta y sólo hablan los personajes dramáticos).

2) Genus enarratiuum (cuando el poeta es el único que habla).

3) Genus commune (cuando hablan tanto el poeta como los personajes). ${ }^{3}$

Esta división en géneros de acuerdo con la persona que habla se remonta, como apunta Curtius, a Platón. Como se recordará, en la República ${ }^{4}$ se establece una distinción entre mimesis y diegesis. Aristóteles alude a este modo en los capitulos iniciales de su tratado; pero, puesto que está interesado en proporcionar una definición de la esencia de la tragedia, pasa a tratar sus partes. Tal vez no sea sino hasta el siglo XX que la pareja de conceptos de diégesis y mímesis vuelvan a cobrar cierta notoriedad y vigencia teórica con el enfoque narratológico de Gérard Genette. ${ }^{5}$

Con el caso anterior se puede ver que difícilmente se puede hablar de categorias universales, válidas para todo periodo o época. ¿Con las triadas aristotélica y diomédica podriamos dar cuenta de géneros caros a nuestro siglo como la autobiografia, la crónica o el ensayo? O retomando la pareja inicial, ¿de qué manera la noción de nonfiction puede explicar el género autobiográfico

2 Michal GlownSKl, "Los géneros literarios”, en Marc ANGENOT et al., Teoria literaria. México, Siglo XXI, 1993, p. 93.

3 Enst Robert CURTIUs, Literatura europea y Edad Media latina. México, FCE, 1955, p. 624.

4 Platon, República, pp. 392-394.

${ }^{3}$ Cf. Narrative Discourse. Oxford, Blackwell, 1980, pp. 162-170. 
que debe tanto a las estrategias narrativas propias de la novela?, o ¿de qué modo seria pertinente cuando se ha llegado a producir novelas catalogadas como fact-fiction? Estas preguntas desbordan la aplicabilidad de estos términos y la cuestión se complica -como veremos en los apartados siguientescuando nos encontramos con denominaciones que combinan dos categorías.

\section{El extraño caso de la alegoría, la comedia y la tragedia medievales}

La obra de Franz Kafka ha sido objeto de todo tipo de interpretaciones, desde psicoanalíticas hasta religiosas. Asimismo, ha servido a críticos como George Steiner para postular su noción de extraterritorialidad, y a alguien como Borges para introducir la idea de que el escritor crea sus propios precursores. En más de una ocasión se ha calificado de al egórica a su obra narrativa. George Lukács, por ejemplo, vio en Kafka el prototipo de la ideología vanguardista, a la vez decadente y solipsista, como una negación de la realidad circundante y totalizante. Siguiendo a Benjamin, Lukács intuyó que la obra de Kafka era un modo de intentar acercarse a una divinidad fantasmagórica - un deus absconditus - que insinúa su presencia, pero que, a final de cuentas, no es más que una ausencia, una vacuidad, como la que oculta una máscara del teatro barroco alemán. ${ }^{6}$ Antes de que se escribiera esto, ya Edmund Wilson se había quejado de este tipo de interpretaciones, y le molestaba que a un relato como "Investigations of a Dog" se le quisiera leer como "an allegory of the relation of man to God" y se minimizaran sus elementos realistas. ${ }^{7}$ Mas, ¿podría establecerse una semejanza entre este tipo de lectura alegórica y la estructura "polisémica" que Dante le atribuye a su Divina comedia?

Recordemos que en la carta a Can Grande, Dante establece, con base en el modelo de interpretación bíblica desarrollado en el medievo, cuatro niveles de sentido: uno literal y tres al egóricos (alegórico, moral y anagógico). ${ }^{8}$ Algo semejante encontrariamos en "A Letter of the Authors" que precede a The Faery Queen, donde Spenser sugiere que su ambiciosa obra es "a continued Allegory, or darke conceit". Notemos que ambas concepciones de alegoría están emparentadas con un repertorio de géneros discursivos cuya vigencia puede ser fechable. Esto se puede ilustrar con un dístico nemotécnico de amplia

${ }^{6}$ Véase The Meaning of Contemporary Realism. Londres, Merlin, 1963.

${ }^{7}$ Edmund Wilson, Classics and Commercials. Nueva York, Vintage, pp. 389-390.

8 Dante Alighieri, "Letter to Can Grande della Scala", en Lionel Trilling, ed., Literary Criticism: An Introductory Reader. Nueva York, Holt, Rinehart and Wiston, 1970 , p. 80. 
circulación durante la Edad Media, y que se ha atribuido, entre otros, a san Agustín:

littera gesta docet, quid credas allegoria, moralis quid agas, quo tendas anagogia.

Estos versos han sido glosados por Robert M. Grant de la siguiente manera:

The letter shows us what God and our fathers did;

The allegory shows where our faith is hid;

The moral meaning gives us rules of daily life;

The anagogy shows us where we end our strife.

La carta de Dante nos remite a toda una formación cultural que está acostumbrada a interpretar el mundo de manera alegórica, y que ve en el mismísimo libro de la naturaleza la impronta divina. Esto dio lugar a todo tipo de excesos exegéticos que a veces rayaban en lo fabuloso, como se puede observar en los bestiarios, donde a Jesús se le asocia con el pelícano, el león o la pantera (encontramos un eco lejano de esto último en Ulysses de Joyce); lapidarios y libros de alquimia que convierten a la piedra filosofal en símbolo de Cristo; o textos que dan razón de las propiedades secretas de las plantas y las maravillas del mundo. No es de extrañar que la postura de santo Tomás de Aquino -quien privilegia el nivel literal o historial por encima de los sentidos alegóricos- se pueda ver como un saludable correctivo ante esta actitud, a veces desmedida, de entablar paralelos, prefiguraciones y analogías por todas partes.

En un interesante y útil artículo, Umberto Eco ha ubicado el lugar que ocupa el texto de Dante dentro de la tradición alegórica. Uno de sus planteamientos es que en la conceptualización medieval, a diferencia de las tendencias del romanticismo en adelante, no hay diferencia entre simbolismo y alegorismo. Eco sitúa la posición del poeta florentino en relación con la interpretación figural y el paso de los tres sentidos postulados por Orígenes -literal, moral (psíquico) y místico (pneumático) - a la tétrada posterior; la críptica simbolización de la divinidad que designa Dionisio Aeropagita como "tiniebla luminosísima"; el papel esclarecedor de san Agustín como protosemiólogo, y la función casi policiaca del Aquinate que acabamos de indicar. ${ }^{10}$

9 Robert M. GRANT, A Short History of the Interpretation of the Bible. Nueva York, Macmillan, 1963, p. 119.

10 Umberto Eco, "La Epistola XIII, el alegorismo medieval, el simbolismo moderno", en Acta Poética, núm. 6, otono de 1986, pp. 7-39. 
La epistola de Dante, sin embargo, parece cumplir otra función aparte de la metatextual, como ha demostrado Curtius. A diferencia de aquellos críticos que ven entre la obra de Dante y el pensamiento escolástico una especie de empatía intelectual, el filólogo alemán señala que el autor de la Divina comedia toma distancia de ciertos presupuestos tomistas, como aquel que asigna un lugar secundario a las obras poéticas en comparación con las disquisiciones filosóficas. Para santo Tomás de Aquino el escaso valor de la poesía se debe, no sólo - como postula la tradición-, a que miente, sino también a que ocupa el escaño más bajo de las ciencias, lugar común de la época que buscaba neutralizar las pretensiones de los auctores a poseer inspiración divina o de tener acceso, por medio de giros metafóricos, al conocimiento verdadero. Curtius prueba cómo Dante se inserta en este tipo de debate y cómo -añadiríamos nosotros- dialoga con estas cuestiones. Curtius ve en la misma estructura de la carta, dividida en partes análogas a los comentarios de un Donato o un Boecio, y en el listado de modus tractandi, indicios de la intención del poeta. Dante enumera diez modos, divididos simétricamente en dos partes. Los primeros cinco (poeticuus, fictiuus, descriptiuus, digressiuus y transumptiuus) caben en el rubro de las artes retóricas, mientras que los cinco restantes (diffinitiuus, diuisiuus, probatiuus, improbatiuus, et exemplorum positiuus) forman parte del método escolástico. ¿Qué pretende Dante con esta lista curiosa? En primer lugar, parece insinuar que el lenguaje poético está al mismo nivel que el discurso filosófico. Por lo que la epístola podría verse como un alegato en favor de la dignidad de la poesía. Además, sería una forma velada de refutar las objeciones tomistas antes mencionadas. Como dice Curtius: "Dante reivindica para su poema la función científica que la escolástica negaba a la poesía en general"."11 Y resulta un gesto simbólico y revelador que, de una gran cantidad de "modos" conocidos como indica Curtius, sólo escoja diez. Este número perfecto parece la contraparte análoga de la arquitectura simétrica de la Divina comedia, dividida en tres partes y compuesta de cien cantos.

La cuestión genérica se torna más complicada una vez que nos damos cuenta de que nos encontramos ante una obra que pretende ser leída a varios niveles y que, además, se presenta como "comedia". Para distinguirla de la tragedia, Dante afirma que: "comedy introduces some harsh complication, but brings its matter to a prosperous end", ${ }^{12}$ lo cual indicaría la trayectoria general de la obra, el ascenso hacia el paraíso, a diferencia de la tragedia que representa la caída del protagonista. Esto nos remite al concepto de tragedia vigente durante la

" E. R. CURTIUS, op. cit., pp. 305-320.

12 D. Alighieri, "Letter to Can Grande della Scala", en L. Trillng, ed., op. cit., p. 81 . 
Edad Media. Chaucer, por ejemplo, al final de Troilus and Cryseide llama a su poema: "litel myn tragedye"; y pide a Dios: "So sende myght to make som comedye". Esta noción de tragedia se presenta de manera más explícita al inicio de "The Monk's Tale", donde encontramos esta suerte de definición:

I wol biwaille, in manere of tragedie,

The harm of hem that stoode in heigh degree

And fillen so that ther nas no remedie

To brynge hem out of hir adversitee

For certein, whan that Fortune list to thee,

Ther may no man to cours of hire withholde.

Let no man truste on blynd prosperitee;

Be war by thise ensamples trewe and olde.

(VII, pp. 1991-1996)

Esto nos indica que el concepto medieval de tragedia -en tanto obra narrativa, no-dramática - funciona con coordenadas muy diferentes a las de la tragedia griega, donde nociones como harmatia, peripeteia, anagnorisis y katharsis se refieren no sólo a otras categorías literarias, sino a un horizonte conceptual diverso, en el que el héroe, de dimensiones humanas, busca equipararse con los dioses y se responsabiliza de su destino. Mientras que en la tragedia medieval la caída parece depender más de los caprichos de la diosa Fortuna (comparada con la cambiante luna en Carmina Burana) que de los errores de juicio de los personajes. El relato de Chaucer presenta el siguiente subtítulo: "Heere bigynneth the Monkes Tale De Casibus Virorum Illustrium". Estas palabras aluden a una obra de Boccaccio, de la cual Chaucer toma varios de sus ejemplos, y que encuadran con claridad con el concepto de tragedia del que venimos hablando. Alan S. Downer ha acuñado el término "de casibus tragedy" para obras dramáticas que tratan de la caida de príncipes y figuras eminentes - como Tamburlaine o Fausto- y le sirve para contrastarlo, dentro del entorno del teatro isabelino, con la tragedia de venganza y la tragedia doméstica. ${ }^{13}$

$\mathrm{Y}$, como indica Atkins, todavía podríamos encontrar otro sentido de comedia en la Edad Media: "Comoedia came to be regarded as a narrative in elegiac verse, written in familiar style and with a happy ending; and this conception resulted in the appearance of a new literary genre in the twelfth century, namely, the medieval comedy which was none other than a versified tale". ${ }^{14}$

${ }^{13}$ Alan S. Downer, The British Drama. Nueva York, Appleton-Century-Crofts, 1950, pp. 125-134.

${ }^{14}$ J. W. H. ATKINS, English Literary Criticism: The Medieval Phase. Londres, Methuen, 1952, p. 32. 
Como se puede ver en la cita anterior, el término conlleva un cierto valor estilístico, y esto es algo que Dante también deja entrever en su carta: "And hence it is evident that the title of the present work is "the Comedy". For if we have respect to its content, at the beginning it is horrible and fetid, for it is hell; and in the end it is prosperous, desirable, and gracious, for it is Paradise. If we have respect to the method of speech, the method is lax and humble, for it is the vernacular speech in which very women communicate". ${ }^{15}$

Por lo tanto, se puede asumir que la oposición tragedia/comedia funciona en varios niveles, ya sea en relación con el tema o contenido, con el estilo en que la obra esté escrita, o con el tipo de personajes que participan en ella. Respecto del estilo, Dante, en el Tratado de la lengua vulgar (II, iv), habla de tres tipos: illustris, mediocris y humilis, estilos propios para la tragedia, la comedia y la elegía, respectivamente. ¿Cuál sería el estilo de la Divina comedia? La obra no estaría supeditada a un solo estilo, como apunta Dante, ya que combinaría, además del estilo vernáculo propio de la "comedia", la canción bucólica, la elegía y la sátira. Dejemos la última palabra de esta sección a Alaistair Fowler, un especialista de los géneros literarios:

We may be inclined to think of medieval literature as a generic wasteland or labyrinth. There are signposts, but these only confuse matters further by their baffling ambiguities. They may be classical, or classical misunderstood, or classical reinterpreted, or vernacular equivalent, or vernacular oblivious, or vernacular artful and innovative. However, as the existence of fairly sophisticated epistolary rhetoric shows, all this is not to be put down to mere incapacity - still less to disregard for genre. ${ }^{16}$

\section{Relativismo histórico y constantes genéricas}

Si de algo pudiera servir este largo ejemplo sería, en primer lugar, para hacer patente que un género literario no se puede definir sin tomar en cuenta las coordenadas y los puntos de referencia activos en un periodo literario especifico. No es lo mismo hablar de tragedia griega como la define Aristóteles, que de tragedia isabelina como la practica Shakespeare. Tampoco se pueden hacer equiparables la novela de detectives, tipo enigma como las de Agatha Christie,

${ }^{15}$ D. Alighieri, "Letter to Can Grande della Scala", en L. Trilling, ed., op. cit., pp. 81-82.

${ }^{16}$ Alaistair Fowler, Kinds of Literature. Oxford, Oxford University Press, 1982, p. 146. 
con la novela negra estadounidense, como las escritas por Raymond Chandler. Mas, ¿cómo podríamos identificar esas coordenadas y puntos de referencia? Uno de los criterios que hemos seguido es recurrir a metatextos - los cuales pueden encontrarse en cartas, ensayos, manifiestos o incluso en las mismas obras de creación- que nos ayuden a definir un concepto particular de literatura. Tal es el papel que han tenido la "Epístola XIII" y los versos iniciales de "The Monk's Tale" en el apartado precedente. Para decirlo con Jurij Lotman: "At the highest grade of organization literature marks out a group of texts which are of a level more abstract than that of the entire remaining mass of texts, i.e., which are metatexts. These are norms, rules, theoretical tracts and critical articles, which turn literature back on itself but in an organized, structured and evaluated form". ${ }^{17}$ A la epistola de Dante se le ha llamado "autoexégesis", pero sería mejor verla como un documento - y aquí pasan a segundo plano las dudas sobre su autoría- que nos ayuda a reconstruir cómo se conceptualizaban los géneros en la Edad Media. De esta manera se puede recuperar la noción de intención, desterrada del vocabulario teórico tanto por los representantes del new criticism como por los estructuralistas y postestructuralistas, reciclándola y asignándole un valor heurístico.

Lotman menciona dos funciones inmediatas del metatexto: una excluyente y otra jerarquizante. Por un lado, sirve para desplazar o neutralizar las obras que no siguen la poética a la que se adhiere el autor o el crítico; por el otro, establece una tabla de valores. Cada época recurre a ciertos criterios de legitimación que deslindan las líneas divisorias de lo que se acepta como literario, valioso o útil. Así, si nos movemos hacia el siglo XviII inglés podríamos comprobar que la norma literaria de los escritores conocidos como Augustans no es la misma que la de un autor como Daniel Defoe. En las plumas de Pope, Swift o Gay encontramos una tendencia marcada hacia la alusión, la reescritura y el juego intertextual que no existe en Robinson Crusoe o Moll Flanders. Esta vena paródica que ironiza y juega con las convenciones de las formas clásicas - y que de modo equívoco se ha dado en llamar neoclásico ${ }^{18}$ - difiere en mucho del incipiente "realismo formal" que un crítico como lan Watt percibe en la narrativa de Defoe. ${ }^{19}$ Consecuentemente, se puede decir que resultó vana e ilusoria la búsqueda estructuralista -imitación del gesto fundacional saussureano- por establecer un sistema abstracto de lo literario. Con el tiem-

17 Jurij Lotman, "The Content and Structure of the Concept of 'Literature", en PTL, núm. 1, 1976, p. 344.

18 Donald GREENE, The Age of Exuberance: Backgrounds to Eighteenth-Century English Literature. Nueva York, Random House, 1970, pp. 159-162.

19 Ian WATT, The Rise of the Novel. Harmondsworth, Penguin, 1972, pp. 9-37. 
po nos hemos percatado de que en un momento dado conviven varios "conceptos" de literatura que pugnan por sobresalir o trascender.

Lo anterior, empero, no invalida los intentos por identificar ciertas constantes o elementos recurrentes en un género. Ésta es una empresa válida que ha formado parte de la crítica y el quehacer teórico, desde los esquemas analiticos de Aristóteles en adelante. Este tipo de tentativa globalizante aparece periódicamente en el ámbito de la crítica literaria, y tal vez a eso se deba la insatisfacción que deja un libro tan ambicioso y tan bien documentado como Anatomy of Criticism (1957). Uno se queda con la sensación de que la empresa de Frye no termina de cuajar, ya que sigue dos proyectos paralelos. Por una parte, quiere establecer una documentación histórica rigurosa y erudita, y, además, aventura una hipótesis de los arquetipos de la literatura universalista y totalizante. Consideremos una de las categorías que maneja: la de romance, que funciona dentro de su esquema bajo tres rubros, como "modo" ("A conventional power of action assumed about the chief characters in fictional literature"), como "mythos" ("narrative pregeneric elements" o "generic plots") y como género en prosa. Respecto al modo, el héroe del romance tiene una superioridad de grado sobre sus congéneres humanos y su entorno, y es capaz de realizar prodigios; es el héroe típico de leyendas y cuentos de hadas. En cuanto "mythos" del verano, el romance es la trama arquetípica de la aventura y la búsqueda trascendente o empresa ("quest"), con sus pruebas respectivas. $Y$ en lo que concierne al género, el romance se opone a la novela. No creo que sea necesario indicar las incongruencias del esquema de Frye (por ejemplo, en el ensayo de 1951, "The Archetypes of Literature", el romance se asocia con la primavera y no con el verano), ya Todorov ha discutido su inconsistencia metodológica, ${ }^{20}$ por lo que está de más abundar en ello. Aun a pesar de estas limitantes, es menester reconocer los constantes destellos y comentarios iluminadores que Frye nos ofrece a lo largo de su libro, mismos que han hecho de Anatomy of Criticism un clásico de la critica moderna.

Mas tratemos de reformular el problema de otro modo: ¿tendrian algo en común las diferentes formas del romance? Hagamos un listado de sus principales apariciones en la literatura inglesa:

a) Chilvalric romance.

b) Pastoral romance.

c) Shakespearean romance.

d) Gothic romance.

${ }^{20}$ Tzvetan TODOROV, Introducción a la literatura fantástica. México, Premiá, 1980, pp. 11-19. 
e) Historical romance.

f) Scientific romance.

g) Women's romance.

Si regresamos a las categorías de Frye veríamos que su noción de modo es aplicable solamente a a) y f). El punto de vista del "mythos" requeriría un análisis más detallado, que no podemos llevar a cabo aquí. Sin embargo, se puede apuntar que los romances shakespeareanos se empalmarían, como señala el propio Frye, en algunos casos con el "mythos" de la comedia, y el "mythos" del verano difícilmente podría dar cuenta de los "women's romances". Por último, el ritmo de la prosa no es aplicable, o sólo parcialmente, a los primeros tres tipos de las formas mencionadas arriba.

Busquemos una forma menos ambiciosa y más económica de atacar el problema. De la lista se pueden hacer varias generalizaciones empíricas. En primer lugar, la preponderancia, salvo el caso c), de obras narrativas. En segundo término, la transición de formas en verso a formas en prosa, con el paso intermedio de b), en que se combinan ambas. La mayor parte de las obras que abarca esta lista comparten un aura de magia y misterio, la incidencia de eventos maravillosos, la idealización de los personajes y, en algunos casos, cierta dosis de escapismo. Se podría hablar de algunos elementos recurrentes, pero a final de cuentas tendríamos que contrastarlos con otras formas sincrónicas de prestigio literario. Así, a) se opondría a la épica o al cantar de gesta; d) y e) a la novela con elementos realistas, y g) se encasillaría al lado de otros géneros narrativos de mucha popularidad y poco renombre literario en este siglo, como la novela policiaca y el género de la ciencia ficción. Cada forma requeriría de un tratamiento especial para ubicarla dentro de las normas y los códigos literarios de sus coetáneos, y no los comentarios apresurados que hemos expresado. ${ }^{21}$

Si tratáramos de contextualizar el teatro isabelino de acuerdo con estos parámetros, nos podriamos dar cuenta de que lo que a primera vista parece como la más ridícula de las categorías que nos endilga Polonio, reproducida al inicio de este artículo, no carece - dentro de la dramaturgia shakespeareanapor completo de sentido. De este modo veríamos que, dentro de la producción

${ }^{21}$ Al respecto, André Lefevere, citando a Jauss, hace el siguiente señalamiento: “A historical/relativistic study of genre will therefore start from the premise that 'literary genres should not be understood as genera (classes) in the logical sense, but as groups or historical families. As such they cannot be derived or defined, but only described, delimited and identified from a historical point of view" ("Systems in Evolution: Historical Relativism and the Study of Genre”, en Poetics Today, vol. 6, núm. 4, 1985, p. 670). 
última de Shakespeare -es decir, las obras conocidas como romances- algo catalogado como "tragical-comical-historical-pastoral" no sería una descripción inexacta de una obra como Cymbeline. Recordemos que en el folio de 1623, Heminges y Condell la colocaron como la última de las tragedias, decisión que desconcertó a más de un crítico. Ahora reconocemos que la acción sigue una trayectoria trágico-cómica, que la hermanan con The Winter's Tale o con Pericles. Las fuentes, como es casi siempre el caso con Shakespeare, combinan material literario e histórico de procedencia diversa: parte de la historia de Posthumus e Imogen se origina en un relato de Boccaccio; la figura de Cimbelino, monarca británico coetáneo de Julio César, proviene de las crónicas de Holinshed; la pérdida de sus hijos Guiderius y Arviragus es una transformación significativa del bardo inglés. Esta laxitud temporal alarmó sobremanera el sentido del decoro poético de un crítico neoclásico como Samuel Johnson. ${ }^{22}$ El cuarto elemento, el bucólico, está anticipado por Imogen cuando, al ser expulsado de la corte su flamante marido por el airado suegro, exclama:

Heaven restore me! Would I were

A neatherds's daughter, and my Leonatus

Our neighbor shepherd's son.

(I, i, pp. 149-150)

Aquí la ironía dramática anticipa tanto su adopción por parte de Belarius como el escenario campestre que domina los actos III y IV. Por otra parte, no debemos perder de vista que la separación de amantes y seres queridos, el exceso de peripecias, la preservación de la virtud bajo todo tipo de amenazas, los rescates de último momento, y la reunión y renconciliación final acercan a Cymbeline con la novela bizantina. Todo esto, así como una aura de asombro mágico, forman parte de los romances shakespeareanos. En conjunto suman una serie de rasgos estilísticos y estructurales que han vuelto inconfundibles las últimas obras dramáticas del bardo inglés. O como diría M. M. Bajtín, quien desarrolló un modelo dialógico-discursivo de los géneros: "Donde existe un estilo, existe un género". 23

${ }^{22}$ En su edición de 1765 dice lo siguiente: "To remark the folly of the fiction, the absurdity of the conduct, the confusion of the names and manners of different times, and the impossibility of the events in any system of life, were to waste criticism upon unresisting imbecility, upon faults so evident for detection and too gross for aggravation", citado por Richard Hosley en la edición Signet de Cymbeline, p. xxxiv.

${ }^{23}$ M. M. BAJTín, "El problema de los géneros dicursivos", en Estética de la creación verbal. México, Siglo XXI, 1982, p. 254. 